\title{
Mesalazine suppository for the treatment of refractory ulcerative chronic radiation proctitis
}

\author{
CHANGLIANG WU, LIYU GUAN, LI YAO and JIEAN HUANG \\ Department of Gastroenterology, The Second Affiliated Hospital of Guangxi Medical University, \\ Nanning, Guangxi 530007, P.R. China
}

Received March 9, 2016; Accepted June 25, 2018

DOI: $10.3892 /$ etm.2018.6464

\begin{abstract}
The aim of the present study was to investigate the safety and efficacy of mesalazine suppository in the treatment of refractory ulcerative chronic radiation proctitis (CRP). In total, 10 refractory ulcerative CRP patients who did not respond to previous medical treatments were recruited for the present study and were treated with mesalazine suppository $(0.5 \mathrm{~g})$ twice daily for 24 weeks. For each patient, the severity of clinical symptoms and endoscopic appearance was assessed before and after the treatment. For symptom scoring, the reductions in the mean total symptom score (pre- vs. post-treatment, 8.20 vs. $0.90 ; \mathrm{P}<0.01$ ), rectal bleeding score $(2.40$ vs. $0.30 ; \mathrm{P}<0.01)$, rectal pain score ( 2.00 vs. 0.50 ; $\mathrm{P}<0.01)$, stool frequency score $(2.00$ vs. $0.10 ; \mathrm{P}<0.01)$ and tenesmus score $(1.80$ vs. $0.00 ; \mathrm{P}<0.01)$ were all statistically significant. For mucosal damage scoring, there was a reduction in the mean scores for total scores (9.22 vs. 5.22; $\mathrm{P}<0.01)$, telangiectasia (2.78 vs. $1.89 ; \mathrm{P}=0.009)$, edema (2.89 vs. 1.78 ; $\mathrm{P}=0.001)$ and ulceration (2.44 vs. 0.89; $\mathrm{P}=0.003)$. However, statistically reductions in the median symptom scores were not observed for stenosis ( 0.78 vs. $0.67 ; \mathrm{P}=0.347)$ and necrosis ( 0.33 vs. $0.00 ; \mathrm{P}=0.081$ ). Furthermore, no adverse events were observed during and after the treatment. The topical mesalazine suppository may be a safe and effective treatment for CRP, particularly for patients with deep ulcers. Adequately randomized controlled trials are required to confirm the results of the present study.
\end{abstract}

Correspondence to: Professor Jiean Huang, Department of Gastroenterology, The Second Affiliated Hospital of Guangxi Medical University, 166 Daxue Dong Road, Nanning, Guangxi 530007, P.R. China

E-mail: jieanh@163.com

Abbreviations: ARP, acute radiation proctitis; CRP, chronic radiation proctitis; HBOT, hyperbaric oxygen therapy; 5-ASA, 5-aminosalicylic acid; APC, argon plasma coagulation; RFA, radiofrequency ablation

Key words: mesalazine suppository, refractory chronic radiation proctitis, clinical efficacy

\section{Introduction}

Radiation treatment, which is an essential therapeutic tool for pelvic malignancies, can cause both acute and chronic radiation proctitis. Acute radiation proctitis (ARP) is defined as occurring within 3 months of radiotherapy and is often self-limiting. Chronic radiation proctitis (CRP) occurs 3 to 6 months after radiotherapy or even years later (1-4). The clinical symptoms of CRP include diarrhea, rectal pain, increased defecate frequency, tenesmus, rectal bleeding, strictures, deep ulcers and fistulas. Although the symptoms of many CRP patients may spontaneously, for some patients who are more critically ill, it may develop to persistent rectal bleeding, deep ulcers and even fistulas that may deeply affect the patient's quality of life $(5,6)$. Nowadays, there are no clearly defined treatment guidelines for CRP and therapeutic modalities include topical and oral agents, endoscopic treatments, formalin application, hyperbaric oxygen therapy (HBOT) and surgery. To date, the majority of clinical trials have focused on controlling rectal bleeding, which is thought to be a common complication of CRP (7-9). Although a deep rectal ulcer is not as common as rectal bleeding in CRP patients, persistent deep rectal ulcers may result in complications, such as stricture and fistulas. However, the data available on the treatment of CRP with deep ulcers is limited and requires further study.

Mesalazine, also known as 5-aminosalicylic acid (5-ASA), has been extensively studied in inflammatory bowel disease and the majority of the data has shown that it is a simple, safe and effective way to treat ulcerative colitis and Crohn's disease. Numerous studies have been performed to investigate the efficacy of 5-ASA and its precursors in the treatment of CRP but the results were inconsistent (10-13). Mesalazine is formulated for oral ingestion and rectal administration. A previous study conducted by Seo et al (12) demonstrated that a combination of oral and topical mesalazine may be a safe and effective treatment of the first episode of CRP, particularly for hemorrhagic proctitis. Unlike previous studies, the present study pays more attention to CRP with rectal ulcers. The aim of the present study was to evaluate the efficacy and safety of topical mesalazine suppository in the treatment of CRP with rectal ulcers.

\section{Patients and methods}

Subjects. Between January 2010 and December 2015, 10 patients that were diagnosed with refractory CRP were 
recruited at The Second Affiliated Hospital of Guangxi Medical University (Nanning, China). Exclusion criteria were: i) Patients with other bowel disease and with a history of prior irradiation to the pelvis or prior rectal ulcers; ii) patients with relapse or metastasis of a primary tumor and iii) patients who received surgery as part of the treatment of cancer. All patients that were enrolled had deep rectal ulcers and had not responded to previous conventional therapy, including sucralfate, corticosteroids, antibiotic, probiotics and traditional Chinese medicine. All patients were evaluated by the severity of the proctitis by clinical symptoms and endoscopic examination prior to the treatment. Furthermore, patient demographics and clinical data, including age, radiotherapy dose and previous treatment options, were collected. Written informed consent was obtained from all participants. The study was approved by the Ethics Committee of The Second Affiliated Hospital of Guangxi Medical University (Nanning, China).

Treatment methods. All patients were administered $0.5 \mathrm{~g}$ topical mesalazine suppository (Salofalk; Dr. Falk Pharma $\mathrm{GmbH}$, Freiburg, Germany) twice daily for 6 months. During the 2 weeks prior to mesalazine suppository, all patients did not receive any treatments in order to exclude the confounding factors. Patients were followed up by telephone or by an outpatient department visit at 2, 4, 8, 12 and 24 weeks after the initiation of treatment to collect clinical data. Endoscopic evaluation was performed before and after treatment.

Condition assessment criteria. All patients were evaluated by a combination of clinical symptoms and endoscopic examination. Clinical symptoms were graded based on the Subjective Objective Management Analysis (SOMA) scale (Table I). There is no standard endoscopic evaluation criterion for ulcerative CRP. Therefore, the following five common endoscopic characteristics associated with radiation proctitis were evaluated blindly by two endoscopists, mean scores were reported as the final scores: Telangiectasia, edema, ulceration, stenosis and necrosis (Table II).

Statistical analysis. All data were analyzed using SPSS statistical package version 22.0 (IBM SPSS, Armonk, NY, USA). Continuous variables were presented as the means with standard deviation or median (range) according to data distributions. A paired, two-tailed Student's t-test was performed to compare clinical symptoms scores and endoscopic examination scores. $\mathrm{P}<0.05$ was considered to indicate a statistically significant difference.

\section{Results}

Patients and treatments. A total of 10 female patients, which underwent radiotherapy due to cervical cancer and were diagnosed with refractory CRP, were enrolled in the present study. Demographics and clinical data of the patients, including radiation dose and previous treatment options, are listed in Table III. The mean age of all patients was 48.80 years (range, 35-60 years). The mean interval from the conclusion of radiotherapy to the onset of symptoms was 7.6 months (range, 2-12 months), and the mean duration of symptoms before treatment was 7.9 months (range, 5-15 months). The median hemoglobin level was
$101.3 \mathrm{~g} / \mathrm{dl}$ (range, 37.9-126.6 g/dl), and only 2 patients required a blood transfusion before the treatment was initiated.

Symptom score. The SOMA scale was assessed before and 2, $4,8,12,24$ weeks after the initiation of treatment. Following treatment, there were statistically significant improvements in all symptoms. The mean pre-treatment total symptom score was 8.20 and the post-treatment mean score was 0.90 . A total of $50 \%(5 / 10)$ of the patients acquired a clinically complete response (post-treatment total symptom score of 0 ). Additionally, there were reductions in the mean scores for rectal bleeding (2.40 vs.0.30; $\mathrm{P}<0.01)$, rectal pain (2.00 vs. 0.50 ; $\mathrm{P}<0.01)$, stool frequency ( 2.00 vs. $0.10 ; \mathrm{P}<0.01)$ and tenesmus ( 1.80 vs. $0.00 ; \mathrm{P}<0.01)$ before and 24 weeks after the initiation of treatment. The pre- and post-treatment median symptoms scores are shown in Table IV.

A comparison of the total scores at baseline and at week 2 revealed that the difference was statistically significant $(\mathrm{P}<0.01)$, demonstrating that the majority of the patients responded within 2 weeks of treatment initiation. Furthermore, when comparing other symptom scores during the treatment period, the data showed that the median time to improvement of rectal bleeding, stool frequency, tenesmus and rectal pain with mesalazine suppository treatment was 2 , 4 and 8 weeks (Table IV). Furthermore, no patient experienced worsening of his or her symptoms.

Endoscopic score. A total of 9 patients received endoscopic examinations before and at 24 weeks after initiation of treatment. Only 1 patient who suffered vagina-rectum fistula rejected endoscopic examinations after treatment. After treatment, the mean pre-treatment total symptom score was 9.22 and with a post-treatment mean of $5.22(\mathrm{P}<0.01)$. In total, 2 patients (20\%) experienced complete ulcer healing. Additionally, there were reductions in the mean scores for telangiectasia (pre vs. post-treatment, 2.78 vs. 1.89; $\mathrm{P}=0.009)$, mucosal edema (2.89 vs. $1.78 ; \mathrm{P}=0.001)$ and mucosal ulcers $(2.44$ vs. 0.89 ; $\mathrm{P}=0.003)$. However, statistical reductions in the median symptom scores were not observed for stenosis (0.78 vs. 0.67; $\mathrm{P}=0.347$ ) and necrosis ( 0.33 vs. $0.00 ; \mathrm{P}=0.081$; Table V). The patient who suffered vagina-rectum fistula still had a fistula after treatment. The main pathological changes before and after treatment under endoscopic examination are shown in Fig. 1.

\section{Discussion}

The present study assessed the efficacy and safety of the mesalazine suppository in the treatment for CRP patients complicated with rectal ulcers. The data demonstrated that the majority of the patients experienced relief of rectal bleeding, tenesmus, stool frequency and rectal pain symptoms. Furthermore, endoscopic observations showed that this therapy promotes rectal ulceration healing in CRP patients.

Radiation proctitis, which is one of the most common intestinal complications following radiation therapy for pelvic malignancies, can be divided into acute and chronic radiation proctitis. Although radiotherapy techniques have been developed and novel devices exist that spare the rectal exposure, CRP still occurs in 5-20\% of patients after radiotherapy. For mild CRP, they can be resolved 
Table I. Subjective Objective Management Analysis assessment criteria for chronic radiation proctitis symptoms.

\begin{tabular}{lllll}
\hline Score & \multicolumn{1}{c}{ Bleeding } & \multicolumn{1}{c}{ Pain } & Stool frequency & Tenesmus \\
\hline 1 & Not obvious & Occasional & $2-4$ times/day & Occasional \\
2 & $>2$ times/week & Intermittent & $4-8$ times/day & Frequent \\
3 & Often & Sustained & $>8$ times/day & Sustained \\
4 & Gross & Refractory & Out of control & Refractory \\
\hline
\end{tabular}

Table II. Scoring of endoscopic characteristics for chronic radiation proctitis.

\begin{tabular}{|c|c|c|c|c|c|}
\hline Score & Telangiectasia & Congestion/edema & Ulceration & Stenosis & Necrosis \\
\hline 1 & Focal telangiectasia & Focal reddening & Superficial ulcer $<1 \mathrm{~cm}^{2}$ & $\begin{array}{l}\text { Lumen diameter, }>2 / 3 \\
\text { normal range }\end{array}$ & Yes \\
\hline 2 & Multiple non-confluent & Diffuse non-confluent & Superficial ulcer $>1 \mathrm{~cm}^{2}$ & $\begin{array}{l}\text { Lumen diameter, } 1 / 3-2 / 3 \\
\text { normal range }\end{array}$ & No \\
\hline 3 & Multiple confluent & Diffuse confluent & Deep ulceration & $\begin{array}{l}\text { Lumen diameter, }<1 / 3 \\
\text { normal range }\end{array}$ & No \\
\hline 4 & - & - & Perforation/fistula & Obstruction & No \\
\hline
\end{tabular}

Table III. Characteristics of all patients.

\begin{tabular}{|c|c|c|c|c|c|c|c|c|c|}
\hline Case & $\begin{array}{c}\text { Age } \\
\text { (years) }\end{array}$ & $\begin{array}{l}\text { Neoplasm } \\
\text { staging }\end{array}$ & Hypertension & Diabetes & $\begin{array}{c}\text { Smoking } \\
\text { history }\end{array}$ & $\begin{array}{l}\text { Interval }^{\mathrm{a}} \\
\text { (months) }^{\text {monthe }}\end{array}$ & $\begin{array}{l}\text { Duration }^{\mathrm{b}} \\
\text { (months) }\end{array}$ & $\operatorname{HGB}(\mathrm{g} / \mathrm{l})$ & $\begin{array}{l}\text { Previous } \\
\text { treatment }^{\mathrm{c}}\end{array}$ \\
\hline 1 & 42 & IIIA & No & No & No & 4 & 4.0 & 85.0 & $2-6$ \\
\hline 2 & 35 & IIIB & No & No & No & 8 & 17.0 & 37.9 & $1-6$ \\
\hline 3 & 58 & IIIB & No & No & No & 7 & 2.5 & 126.6 & 1,5 \\
\hline 4 & 46 & IIA & No & No & No & 9 & 3.0 & 124.3 & $4-6$ \\
\hline 5 & 41 & IIIB & No & No & No & 7 & 3.0 & 104.5 & $1,2,6$ \\
\hline 6 & 49 & IIB & No & No & No & 8 & 2.0 & 100.0 & 4-6 \\
\hline 7 & 52 & IIIB & No & No & No & 2 & 3.0 & 104.2 & 5,6 \\
\hline 8 & 46 & IIB & No & No & No & 9 & 8.0 & 51.4 & $3,4,6$ \\
\hline 9 & 59 & IIB & Yes & No & No & 12 & 3.0 & 100.3 & 4,6 \\
\hline 10 & 60 & IIB & No & No & No & 10 & 6.0 & 102.3 & 4,6 \\
\hline
\end{tabular}

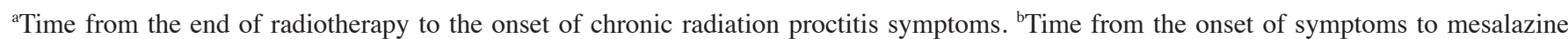
suppository treatment. 'Previous treatment included 1, sucralfate enema; 2, glucocorticoid enema; 3, montmorillonite powder; 4, L-glutamine; 5, antibiotic treatment; and 6, Yunnan baiyao Traditional Chinese Medicine enema. HGB, hemoglobin.

Table IV. Symptom scores of patients pre- and post-treatment.

\begin{tabular}{lcccccccccc}
\hline $\begin{array}{l}\text { Time } \\
\text { (weeks) }\end{array}$ & Total score & P-value & $\begin{array}{c}\text { Rectal } \\
\text { bleeding }\end{array}$ & P-value & Pain & P-value & $\begin{array}{c}\text { Stool } \\
\text { frequency }\end{array}$ & P-value & Tenesmus & P-value \\
\hline Baseline & $8.20 \pm 3.39$ & - & $2.40 \pm 0.97$ & - & $2.00 \pm 0.94$ & - & $2.00 \pm 1.05$ & - & $1.80 \pm 1.03$ & - \\
2 & $5.50 \pm 3.37$ & $<0.01$ & $1.30 \pm 0.95$ & 0.003 & $1.70 \pm 1.16$ & 0.081 & $1.00 \pm 0.94$ & $<0.01$ & $1.50 \pm 0.97$ & 0.081 \\
4 & $3.60 \pm 2.91$ & $<0.01$ & $0.80 \pm 0.79$ & $<0.01$ & $1.50 \pm 1.27$ & 0.052 & $0.40 \pm 0.70$ & $<0.01$ & $0.90 \pm 0.74$ & 0.004 \\
8 & $1.60 \pm 1.90$ & $<0.01$ & $0.40 \pm 0.52$ & $<0.01$ & $0.90 \pm 0.99$ & $<0.01$ & $0.10 \pm 0.32$ & $<0.01$ & $0.20 \pm 0.42$ & $<0.001$ \\
12 & $1.30 \pm 1.89$ & $<0.01$ & $0.30 \pm 0.48$ & $<0.01$ & $0.80 \pm 1.03$ & $<0.01$ & $0.10 \pm 0.32$ & $<0.01$ & $0.10 \pm 0.32$ & $<0.001$ \\
24 & $0.90 \pm 1.29$ & $<0.01$ & $0.30 \pm 0.48$ & $<0.01$ & $0.50 \pm 0.71$ & $<0.01$ & $0.10 \pm 0.32$ & $<0.01$ & - & $<0.001$ \\
\hline
\end{tabular}

Data are presented as the mean \pm standard deviation. 
Table V. Endoscopic scores of patients pre- and post-treatment.

\begin{tabular}{lcccccc}
\hline Time point & Total score & Telangiectasia & Edema & Ulceration & Stenosis & Necrosis \\
\hline Baseline & $9.22 \pm 1.99$ & $2.78 \pm 0.44$ & $2.89 \pm 0.33$ & $2.44 \pm 1.24$ & $0.78 \pm 0.44$ & $0.33 \pm 0.50$ \\
24 weeks & $5.22 \pm 1.39$ & $1.89 \pm 0.60$ & $1.78 \pm 0.67$ & $0.89 \pm 1.27$ & $0.67 \pm 0.50$ & - \\
P-value & $<0.01$ & 0.009 & 0.001 & 0.003 & 0.347 & 0.081 \\
\hline
\end{tabular}

Data are presented as the mean \pm standard deviation.
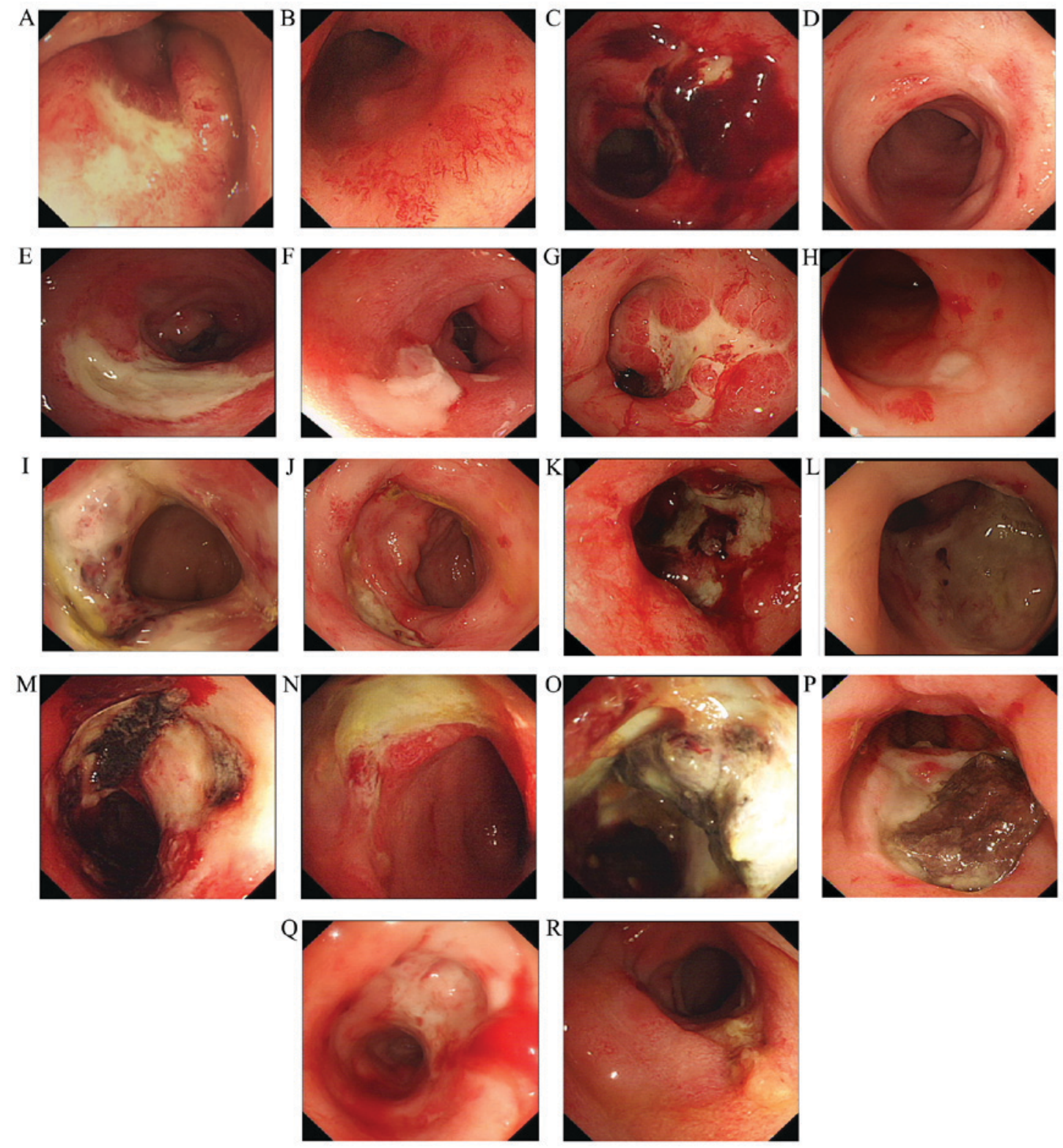

Figure 1. Endoscopic examination of case 1 (A) before and (B) after treatment; case 2 (C) before and (D) after treatment; case 3 (E) before and (F) after treatment; case 4, (G) before and (H) after treatment; case $5(\mathrm{I})$ before and $(\mathrm{J})$ after treatment; case $6(\mathrm{~K})$ before and $(\mathrm{L})$ after treatment; case 7 (M) before and $(\mathrm{N})$ after treatment; case $8(\mathrm{O})$ before and $(\mathrm{P})$ after treatment; and case $9(\mathrm{Q})$ before and $(\mathrm{R})$ after treatment.

spontaneously without any treatment, whereas severe symptoms of CRP, including persistent rectal bleeding, deep ulceration, strictures and fistulas, have a worse prognosis and require treatment to control symptoms $(4,14)$. Furthermore, several treatment options, including drug therapy, endoscopic treatments, formalin application, HBOT and surgery have been used to relieve symptoms of CRP, but none of them have shown convincing efficacy $(2,15)$.

Previous studies have focused on hemorrhagic CRP (7-9), whereas the present study concentrated on CRP patients with rectal ulcerations. All of the patients enrolled in the present study had rectal ulcerations and were not responsive to 
previous treatment modalities. Furthermore, rectal ulceration is not a common complication for CRP, but persistent deep rectal ulceration accompanies evident symptoms and is more likely to lead to stricture, perforation and fistula. Until recently, experiments for treatments of deep ulceration CRP were limited. Although several drugs, including topical sucralfate (9), intestinal probiotics (16,17), steroid enemas (18), short chain fatty acids $(19,20)$, antioxidants (21), antibiotics (22), pentoxifylline (23) synbiotics (17) and traditional Chinese medicine (24) have been used to relieve symptoms of CRP, studies revealed that superior results were observed in patients with mild-to-moderate CRP.

Novel endoscopic therapies, including argon plasma coagulation (APC) and radiofrequency ablation (RFA), are preferred alternatives to control persistent rectal bleeding of CRP (25-27). However, these invasive treatments are not suitable for patients with deep ulceration. The ulceration lesions involve the intestinal muscle and even the serosa layers. Furthermore, invasive endoscopic treatment should be avoided for ulcerative CRP because these treatments may pose the risk of perforation and fistula (28-31). Additionally, intrarectal formalin application also exhibited effective control of rectal bleeding in patients with CRP $(26,27)$. However, the side effects of formalin application include anal stenosis, fissures, fecal incontinence and ulceration of the mucosa; therefore, it was not a good choice for ulcerative CRP $(32,33)$. Furthermore, although HBOT is reported to be an effective treatment for CRP, it is not widely applicable due to its high cost and the specialized equipment required $(34,35)$. Finally, surgery is thought to be the last resort for CRP because of its severe postoperative complications. Therefore, surgery may only be applied for severe and refractory CRP patients who are not responsive to other medical and endoscopic approaches (36,37).

Mesalazine, the active component of sulfasalazine, is considered as an anti-inflammatory drug used to treat inflammatory bowel disease, including ulcerative colitis and Crohn's disease. Furthermore, mesalazine suppository is a bowel-specific formulation that acts locally in the rectum and can increase drug mucosal concentrations and decrease systemic side effects. A number of clinical trials have been performed to investigate the efficacy of 5-ASA and its precursors in the prevention and treatment of radiation proctitis; however, the conclusions remain controversial, with some studies reporting positive results and others showing no effect or even worsening of the symptoms (10-13). Based on previous results, the present study attempted to evaluate the efficacy and safety of topical mesalazine suppository in the treatment of refractory ulcerative CRP. After 24 weeks of therapy, the clinical symptoms were relieved and an endoscopic examination showed marked improvements in the rectal mucosa damage. These results were consistent with the results of Seo et al (12), who conducted a prospective study to investigate the combination therapy with oral and topical mesalazine for patients with a first episode of radiation. After 4 weeks of treatment, they observed that there were statistically significant improvements in rectal bleeding; however, this treatment cannot control the symptoms of pain, tenesmus and stool frequency. Endoscopic observations, including telangiectasia, bleeding point and friable mucosa, also showed a statistically significant improvement after 4 weeks of combination treatment. The present study found that mesalazine suppository therapy was able to not only control rectal bleeding but also relieve the symptoms of tenesmus, stool frequency and rectal pain in CRP. These contradictory observations may be due to a difference in the treatment time between the two studies. Patients in the present study received mesalazine suppository for 24 weeks whereas in the study by Seo et al (12) the patients received only 4 weeks of combination treatment. Furthermore, the present study revealed that rectal bleeding and stool frequency could be alleviated after 2 weeks of treatment, while longer treatments of at least 4 weeks were required to improve the symptoms of tenesmus. Additionally, rectal pain requires at least 8 weeks of treatment for it to be relieved. In the present study, a statistically significant improvement was observed not only in telangiectasia but also in the mucosal edema and ulcerations after longer mesalazine suppository treatment.

The present study had various limitations. There were a small number of cases and no control group. Furthermore, the period of follow-up was not long enough to evaluate the long-term efficacies and complications. In conclusion, compared to other special therapies that are performed in selected centers by skilled operators, have potential complications and are expensive, mesalazine suppository may be a feasible and effective treatment for CRP, particularly in patients with ulcers.

\section{Acknowledgements}

Not applicable.

\section{Funding}

The present study was supported by the Guangxi Provincial Department of Health Topics (grant no. 2013176).

\section{Availability of data and materials}

The datasets used and/or analyzed during the current study are available from the corresponding author on reasonable request.

\section{Authors' contributions}

$\mathrm{CW}$ and $\mathrm{JH}$ designed the study. CW, JH, LG and LY collected the data. LG and LY analyzed the data. CW, LG and LY prepared the manuscript. All authors read and approved the final version of the manuscript.

\section{Ethics approval and consent to participate}

Written informed consent was obtained from all participants. The study was approved by the Ethics Committee of the Second Affiliated Hospital of Guangxi Medical University.

\section{Patient consent for publication}

Not applicable.

\section{Competing interests}

The authors declare that they have no competing interests. 


\section{References}

1. Abayomi J, Kirwan J and Hackett A: The prevalence of chronic radiation enteritis following radiotherapy for cervical or endometrial cancer and its impact on quality of life. Eur J Oncol Nurs 13: 262-267, 2009

2. Mendenhall WM, McKibben BT, Hoppe BS, Nichols RC, Henderson RH and Mendenhall NP: Management of radiation proctitis. Am J Clin Oncol 37: 517-523, 2014.

3. Theis VS, Sripadam R, Ramani V and Lal S: Chronic radiation enteritis. Clin Oncol (R Coll Radiol) 22: 70-83, 2010.

4. Hanson B, Macdonald R and Shaukat A: Endoscopic and medical therapy for chronic radiation proctopathy: A systematic review. Dis Colon Rectum 55: 1081-1095, 2012.

5. Ruiz-Tovar J, Morales V, Hervás A, Sanjuanbenito A, Lobo E and Martínez-Molina E: Late gastrointestinal complications after pelvic radiotherapy: Radiation enteritis. Clin Transl Oncol 11: 539-543, 2009

6. Wallner K, Sutlief S, Bergsagel C and Merrick GS: Severe rectal complications after prostate brachytherapy. Radiother Oncol 114: 272-275, 2015.

7. Sahakitrungruang C, Thum-Umnuaysuk S, Patiwongpaisarn A, Atittharnsakul P and Rojanasakul A: A novel treatment for haemorrhagic radiation proctitis using colonic irrigation and oral antibiotic administration. Colorectal Dis 13: e79-e82, 2011.

8. Dziki Ł, Kujawski R, Mik M, Berut M, Dziki A and Trzciński R: Formalin therapy for hemorrhagic radiation proctitis. Pharmacol Rep 67: 896-900, 2015.

9. McElvanna K, Wilson A and Irwin T: Sucralfate paste enema: A new method of topical treatment for haemorrhagic radiation proctitis. Colorectal Dis 16: 281-284, 2014.

10. Jahraus CD, Bettenhausen D, Malik U, Sellitti M and St Clair WH: Prevention of acute radiation-induced proctosigmoiditis by balsalazide: A randomized, double-blind, placebo controlled trial in prostate cancer patients. Int J Radiat Oncol Biol Phys 63: 1483-1487, 2005.

11. Sanguineti G, Franzone P, Marcenaro M, Foppiano F and Vitale V: Sucralfate versus mesalazine versus hydrocortisone in the prevention of acute radiation proctitis during conformal radiotherapy for prostate carcinoma. A randomized study. Strahlenther Onkol 179: 464-470, 2003.

12. Seo EH, Kim TO, Kim TG, Joo HR, Park J, Park SH, Yang SY, Moon YS, Park MJ, Ryu DY and Song GA: The efficacy of the combination therapy with oral and topical mesalazine for patients with the first episode of radiation proctitis. Dig Dis Sci 56: 2672-2677, 2011.

13. Resbeut M, Marteau P, Cowen D, Richaud P, Bourdin S, Dubois JB, Mere P and N'Guyen TD: A randomized double blind placebo controlled multicenter study of mesalazine for the prevention of acute radiation enteritis. Radiother Oncol 44: 59-63, 1997.

14. Vanneste BG, Van De Voorde L, de Ridder RJ, Van Limbergen EJ, Lambin P and van Lin EN: Chronic radiation proctitis: Tricks to prevent and treat. Int J Colorectal Dis 30: 1293-1303, 2015.

15. Sarin A and Safar B: Management of radiation proctitis. Gastroenterol Clin North Am 42: 913-925, 2013.

16. Spyropoulos BG, Misiakos EP, Fotiadis C and Stoidis CN: Antioxidant properties of probiotics and their protective effects in the pathogenesis of radiation-induced enteritis and colitis. Dig Dis Sci 56: 285-294, 2011.

17. Nascimento M, Aguilar-Nascimento JE, Caporossi C, Castro-Barcellos HM and Motta RT: Efficacy of synbiotics to reduce acute radiation proctitis symptoms and improve quality of life: A randomized, double-blind, placebo-controlled pilot trial. Int J Radiat Oncol Biol Phys 90: 289-295, 2014.

18. Hille A, Schmidberger H, Hermann RM, Christiansen H, Saile B, Pradier O and Hess CF: A phase III randomized, placebo-controlled, double-blind study of misoprostol rectal suppositories to prevent acute radiation proctitis in patients with prostate cancer. Int J Radiat Oncol Biol Phys 63: 1488-1493, 2005.

19. Pinto A, Fidalgo P, Cravo M, Midões J, Chaves P, Rosa J, dos Anjos Brito $M$ and Leitão $C N$ : Short chain fatty acids are effective in short-term treatment of chronic radiation proctitis: Randomized, double-blind, controlled trial. Dis Colon Rectum 42: 788-796, 1999.

20. Talley NA, Chen F, King D, Jones M and Talley NJ: Short-chain fatty acids in the treatment of radiation proctitis: A randomized, double-blind, placebo-controlled, cross-over pilot trial. Dis Colon Rectum 40: 1046-1050, 1997.
21. Kennedy M, Bruninga K, Mutlu EA, Losurdo J, Choudhary S and Keshavarzian A: Successful and sustained treatment of chronic radiation proctitis with antioxidant vitamins $\mathrm{E}$ and $\mathrm{C}$. Am J Gastroenterol 96: 1080-1084, 2001.

22. Sahakitrungruang C, Thum-Umnuaysuk S, Patiwongpaisarn A, Atittharnsakul P and Rojanasakul A: A novel treatment for haemorrhagic radiation proctitis using colonic irrigation and oral antibiotic administration. Colorectal Dis 13: e79-e82, 2011.

23. Hille A, Christiansen H, Pradier O, Hermann RM, Siekmeyer B, Weiss E, Hilgers R, Hess CF and Schmidberger H: Effect of pentoxifylline and tocopherol on radiation proctitis/enteritis. Strahlenther Onkol 181: 606-614, 2005.

24. Wang L, Zhang ZZ, Tu XH, Zou ZD, Liu JH and Wang Y: Safety and efficacy of Qingre Buyi Decoction in the treatment of acute radiation proctitis: A prospective, randomized and controlled trial. Chin J Integr Med 15: 272-278, 2009.

25. Pigò F, Bertani H, Manno M, Mirante VG, Caruso A and Conigliaro RL: Radiofrequency ablation for chronic radiation proctitis: Our initial experience with four cases. Tech Coloproctol 18: 1089-1092, 2014.

26. Dray X, Battaglia G, Wengrower D, Gonzalez P, Carlino A, Camus M, Adar T, Pérez-Roldán F, Marteau P and Repici A: Radiofrequency ablation for the treatment of radiation proctitis. Endoscopy 46: 970-976, 2014.

27. Hortelano E, Gómez-Iturriaga A, Ortiz-de-Zárate R, Zaballa M, Barturen Á, Casquero F, San-Miguel Î, Carvajal C, Cacicedo J, Del-Hoyo O, et al: Is argon plasma coagulation an effective and safe treatment option for patients with chronic radiation proctitis after high doses of radiotherapy? Rev Esp Enferm Dig 106: 165-170, 2014.

28. Canard JM, Védrenne B, Bors G, Claude P, Bader R and Sondag D: Long term results of treatment of hemorrhagic radiation proctitis by argon plasma coagulation. Gastroenterol Clin Biol 27: 455-459, 2003 (In French).

29. Karamanolis G, Triantafyllou K, Tsiamoulos Z, Polymeros D, Kalli T, Misailidis N and Ladas SD: Argon plasma coagulation has a long-lasting therapeutic effect in patients with chronic radiation proctitis. Endoscopy 41: 529-531, 2009.

30. Koessler T, Servois V, Mariani P, Aubert E and Cacheux W: Rectal ulcer: Due to ketoprofen, argon plasma coagulation and prostatic brachytherapy. World J Gastroenterol 20: 17244-17246, 2014.

31. Ravizza D, Fiori G, Trovato C and Crosta C: Frequency and outcomes of rectal ulcers during argon plasma coagulation for chronic radiation-induced proctopathy. Gastrointest Endosc 57: 519-525, 2003.

32. de Parades V, Etienney I, Bauer P, Bourguignon J, Meary N, Mory B, Sultan S, Taouk M, Thomas C and Atienza P: Formalin application in the treatment of chronic radiation-induced hemorrhagic proctitis-an effective but not risk-free procedure: A prospective study of 33 patients. Dis Colon Rectum 48: 1535-1541, 2005.

33. Tsujinaka S, Baig MK, Gornev R, de la Garza C, Hwang JK, Sands D, Weiss EG, Nogueras JJ, Efron J, Vernava AM III and Wexner SD: Formalin instillation for hemorrhagic radiation proctitis. Surg Innov 12: 123-128, 2005.

34. Allen S, Kilian C, Phelps J and Whelan HT: The use of hyperbaric oxygen for treating delayed radiation injuries in gynecologic malignancies: A review of literature and report of radiation injury incidence. Support Care Cancer 10: 2467-2472, 2012.

35. Oscarsson N, Arnell P, Lodding P, Ricksten SE and Seeman-Lodding H: Hyperbaric oxygen treatment in radiation-induced cystitis and proctitis: A prospective cohort study on patient-perceived quality of recovery. Int J Radiat Oncol Biol Phys 87: 670-675, 2013.

36. Wu XR, Liu XL, Katz S and Shen B: Pathogenesis, diagnosis, and management of ulcerative proctitis, chronic radiation proctopathy, and diversion proctitis. Inflamm Bowel Dis 21: 703-715, 2015.

37. Do NL, Nagle D and Poylin VY: Radiation proctitis: Current strategies in management. Gastroenterol Res Pract 2011: 917941, 2011.

This work is licensed under a Creative Commons Attribution-NonCommercial-NoDerivatives 4.0 International (CC BY-NC-ND 4.0) License. 